\title{
NOTES ON THE HABITS AND HABITA'T OF GEOTRUPES CHALYBAEUS LECONTE IN FLORIDA ${ }^{1}$
}

\author{
By Frank N. Young
}

Geotrupes chalybaeus described by LeConte $^{2}$ from fragments found at Tampa, Florida has long been a rarity in collections. This rarity seems to be due to the restricted habitat of the species and to its occurrence in the winter and early spring months. In many areas of "Scrub" vegetation on St. Lucie and other deep sands it is relatively common, and can be trapped in numbers by burying pint jars up to the neck in the ground and placing an inch or so of molasses and water, honey and water, or decaying mushrooms in the bottom. ${ }^{3}$ Careful examination of other unusual habitats and use of different methods of collecting will probably reveal that many "rarities" are really quite common when their exact habitat is known.

In February, 1949, I stumbled upon a "colony" of Geotrupes chalybaeus in a small area of scrub in Putnam County south of Interlachen, Florida. The abundance of this supposedly rare beetle in this situation aroused my interest and subsequent collecting and observation indicated that the species extends over most of the dry sand areas of northern peninsular Florida. Its burrowing habits seem to restrict it to deep sands, and it can probably be expected wherever such occur within its range-possibly as far north as Maryland. There is some indication that local populations differ, but further study will be necessary to determine the significance of this variation.

The area in which the beetles were first observed south of Interlachen is largely covered by a stand of mature sand pines (Pinus clausa $)^{4}$ on St. Lucie sand on top of an elevation completely surrounded by the ground-water podzols of the Leon-St. Johns series

${ }^{1}$ Contribution No. 431 from the Department of Zoology, Indiana University and from the Department of Biology, University of Florida.

${ }^{2}$ Coleoptera of Florida, Proc. Amer. Philos. Soc. 17, 1878: 402.

${ }^{3}$ See also Hubbell, T. H. A monographic revision of the genus Ceuthophilus, Univ. of Fla. Publ., Biol. Sci. Ser., 2(1), 1936, for further notes on methods of using "molasses traps."

${ }^{4}$ Plant names are after Davis, J. H. Natural features of southern Florida, Fla. Geol. Surv., Bull. 25, 1943. 
of "Flatwoods" soils. The area actually represents an island, probably developed as an offshore bar in the Pamlico or earlier sea, of the late Pleistocene epoch. It appears as an isolated, low hill about a mile in diameter (Putnam County, T-11-S, R-25-E, Sec. 17) on the topographic map of Florida (Contour Topographic Map, scale 1:500,000) prepared by the U. S. Engineer Department. The high central part of the "island" is almost pure sand pine scrub surrounded by a zone of Quercus laevis-Pinus palustris associes which grades through an ecotonal belt of Quercus cinerea-Pinus palustris/ Pinus elliotti into the Pinus palustris-Aristida associes on Leon sand -in local terms "Scrub" surrounded by "High Pine-Turkey Oak" grading through "High Pine-Blue Jack Oak" into "Long Leaf Pine Flatwoods".

Large specimens of the sand pine (Pinus clausa) cover the central portion of the "island" so closely that there is almost no ground vegetation except for a few small and scattered scrub oaks (Quercus chapmani, $Q$. myrtifolia, and $Q$. virginiana geminata), straggling patches of sedges and wire grass, and a few stunted Xolisma, Garberia, and other shrubs. A very few specimens of Ceratiola ericoides, the Scrub Rosemary, were found after some searching. The surface of the sand beneath the trees is covered with a thin mat of pine needles which together with an occasional fallen pine trunk, scattered plants of reindeer moss (Cladonia spp.), and occasional polypore and other mushrooms give the surface a characteristic aspect. The porous nature of the soil makes this a very dry situation. It was noticed on several occasions that the surface sand would be quite dry a short time after a heavy rain.

In late February, I found yellowish mounds of sand scattered over the pine needle mat in every direction. It was soon discovered that these mounds marked the burrows of Geotrupes chalybaeus since an occasional specimen could be dug out of the burrow beneath a mound by quickly thrusting a trowel or shovel into the ground so as to intercept the burrow. In a relatively small area, about 50 by 100 feet, along the western edge of the pines almost a thousand mounds were counted. This was the maximum density encountered, although some were found almost everywhere the sand pines occurred. Not all were fresh, many showing the slumping effect produced by rains, and some were so old that only the difference in color indicated their former position.

A series of "molasses traps" was extended from the edge of the 
scrub area across the thickest concentration of the mounds and about 150 feet farther into the pines. About 50 jars and cans were used placed about 5 to 10 feet apart. Several days later, as many as $15 \mathrm{G}$. chalybaeus were found in a single jar, the number generally being highest near the greatest concentration of mounds. No specimens were taken in the five traps which extended outside the sand pine area, probably because of the density of the wiregrass which interfered with the movements of the beetles.

\section{Burrowing Habits}

Geotrupes chalybaeus is a remarkable burrower. The burrows beneath the mounds or "throwups" descend practically straight down, and apparently offer no particular difficulties to excavation, but the loose sand falls into burrows so readily it is very difficult to reach the bottom. In early March, several burrows were excavated to a depth below $60^{\prime \prime}$ below which they were lost or the sand caved in upon them. One burrow was excavated to a depth of $61^{\prime \prime}$ at which point it turned abruptly at right angle and ran $3^{\prime \prime}$ more before coming to an end at which a small female beetle was found among some pine needles and male pine cones. None of the burrows excavated gave any clue as to the possible larval or adult food. Old burrows which might have contained larval chambers could not be traced because they had filled with sand to within a short distance of the surface.

The mounds or "throwups" are quite characteristic and easily identified once they have been seen. Groups of typical mounds found in many places seldom failed to produce at least a token specimen or be associated with fragments caught in spider webs beneath logs or rocks. In size the G. chalybaeus "throwup" is intermediate between that of smaller Geotrupes, Bolboceras, etc. and the smallest pocket gopher mounds. A typical "throwup" is about 6 " long by $5^{\prime \prime}$ wide by $1 \frac{1}{2}$ to $2^{\prime \prime}$ high. The burrow (about $7 / 8$ " in diameter) opens under one end of this small mound and is usually loosely closed with a plug of damp sand. In the fresh burrows a small clump of roundish roll of damp sand broken into small segments indicates the end of the mound at which the burrows opens. Occasionally this roll of damp sand was seen being pushed out of the burrow, and once a beetle was taken by thrusting a trowel into the soil beneath the end of the roll. It seems very probable that the beetle excavates its burrow by bringing up small pellets of damp sand from the bot- 
tom and pressing them against the bottom of a plug which is gradually forced out upon the surface. Such a method would allow the burrow to be closed most of the time, which might be of value in preventing excess evaporation in so xeric an environment. Burrows in which the mouth was open were in many cases filled with sand a little ways beneath the surface. This sand seemed to have been washed in rather than being a plug formed by the beetles.

\section{Aboveground Activities}

Night observations revealed a few males and females on the surface among the mounds. No feeding, mating, or other activities were observed, however, since all specimens found were lying on the pine needle mat and did not move while under observation which in some cases lasted as long as half an hour. The smaller size of the females in relation to the males and the grouping together of the mounds suggests that some sub-social activity might be expected. Presence of light in the area and other activity may have disturbed the beetles because the trapping results indicated that there was considerable wandering about at night.

\section{Food}

The only information on food is indirect. Adult beetles were attracted to molasses and water, honey and water, decaying mushrooms, and molasses-honey-mushrooms and water. Some specimens were trapped in empty jars or jars containing only water. Jars containing cow manure, horse dung, or human excreta seemed to repel the beetles since none were taken in such traps although others in the same area fell into empty jars. Molasses and honey caught more beetles than decaying mushrooms, but the latter did not trap the beetles as did the sticky solutions so that many more may have visited the mushrooms and then left. The amount of possible food in such a situation as the "Scrub" is rather limited, but mushrooms and various lichens are frequently very abundant.

\section{Distribution In Florida}

"Throwups" accompanied by fragments or specimens of G. chalybaeus were found in a number of places in northern peninsular Florida. All were located in areas of St. Lucie, Lakeland, Chiefland, or Orlando sands. None were found in St. Lucie or Dade sands in 
southern Florida during June, 1949, but search in the period from January to May might reveal them. The largest "colony" found beside the one near Interlachen was near Belleview in Marion County. Several hundred "throwups" were found there in deep Lakeland sand supporting the Quercus laevis-Pinus palustris associes. Typical "throwups" were also found in the "Big Scrub" south of the Oklawaha River, but no beetles were taken.

Florida counties from which records were established are: Gilchrist (2 localities), Levy (2 localities), Alachua (2 localities, also records by T. H. Hubbell), Putnam [3 localities, also Welaka (A. F. Van Pelt and J. C. Moore), and north of Palatka (H. K. Wallace)], Volusia (1 locality), Marion (2 localities), and Hernando (1 locality.) All of these localities were in areas of Pinus clausa-Ceratiola ericoides associes or Quercus laevis-Pinus palustris associes. In nearly all cases they were associated with mounds of pocket gophers (Geomys spp.) and the gopher tortoise (Gopherus polyphemus).

All specimens are in the collection of the University of Michigan Museum of Zoology, Ann Arbor, Michigan.

Chalepus bicolor OLIv. (Coleoptera).-This species has not been listed north of Connecticut but I took one here on June 19, 1942, by sweeping. About a dozen were taken here on August 2 and 10, 1947, on Panicum scribnerianum Nash. The determination of this grass was obtained through the kindness of Dr. I. M. Johnston of the Arnold Arboretum. Another specimen of the beetle was obtained by sweeping in the Quabbin Reservation in Ware, Mass., June 26, 1947. My other specimens are from South Carolina, Indiana, Florida and Connecticut.-C. A. Frosr, Framingham, Mass. 

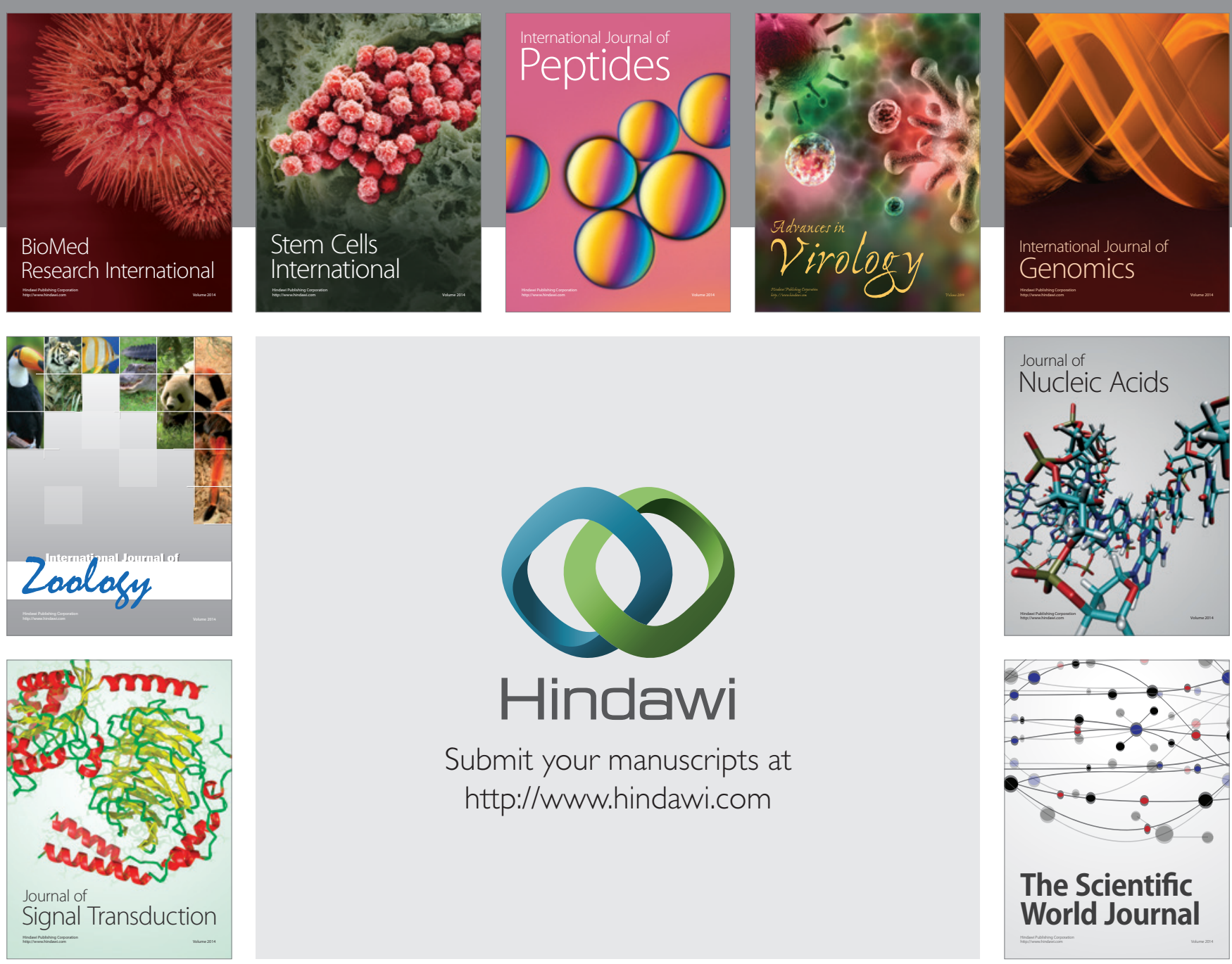

Submit your manuscripts at

http://www.hindawi.com
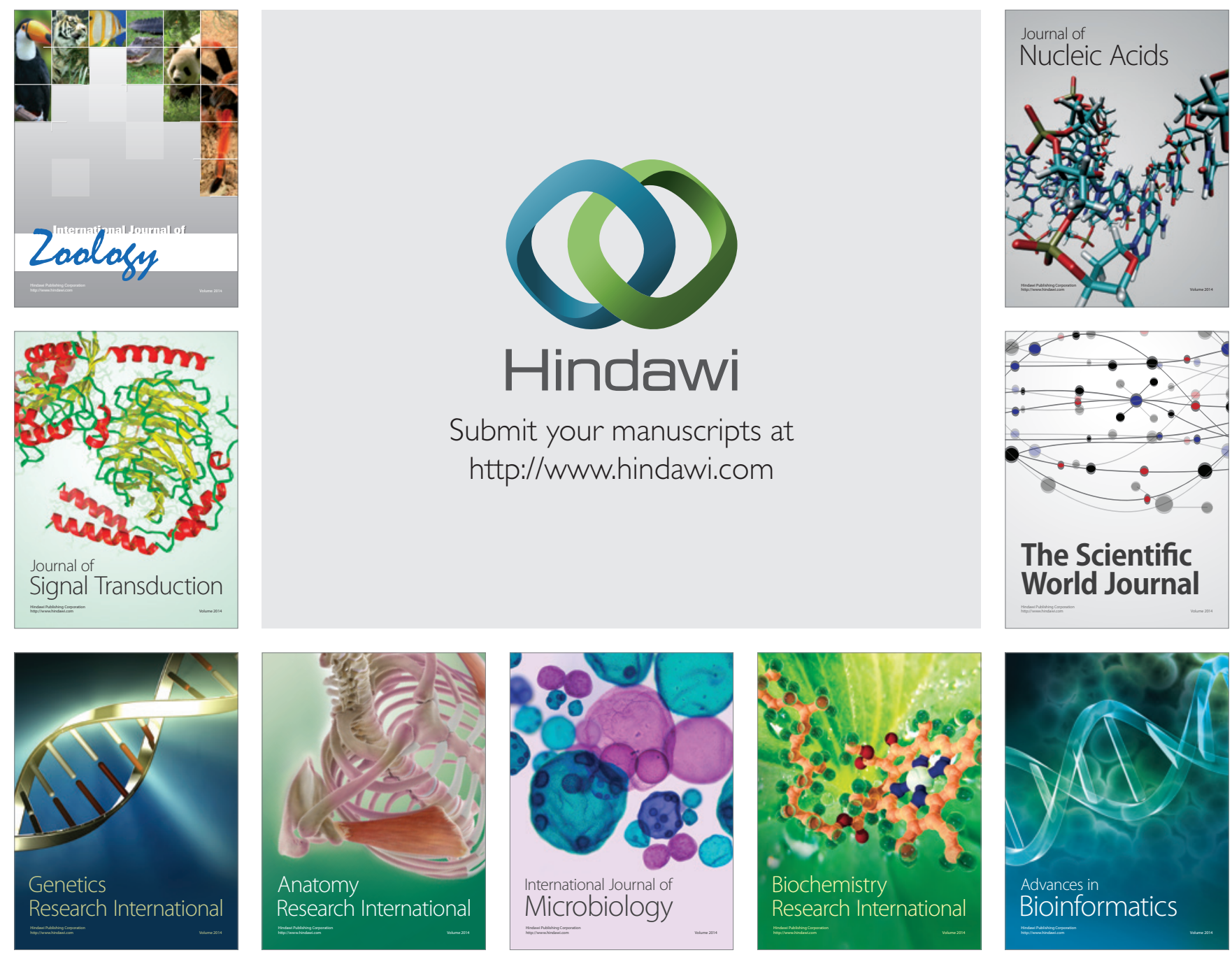

The Scientific World Journal
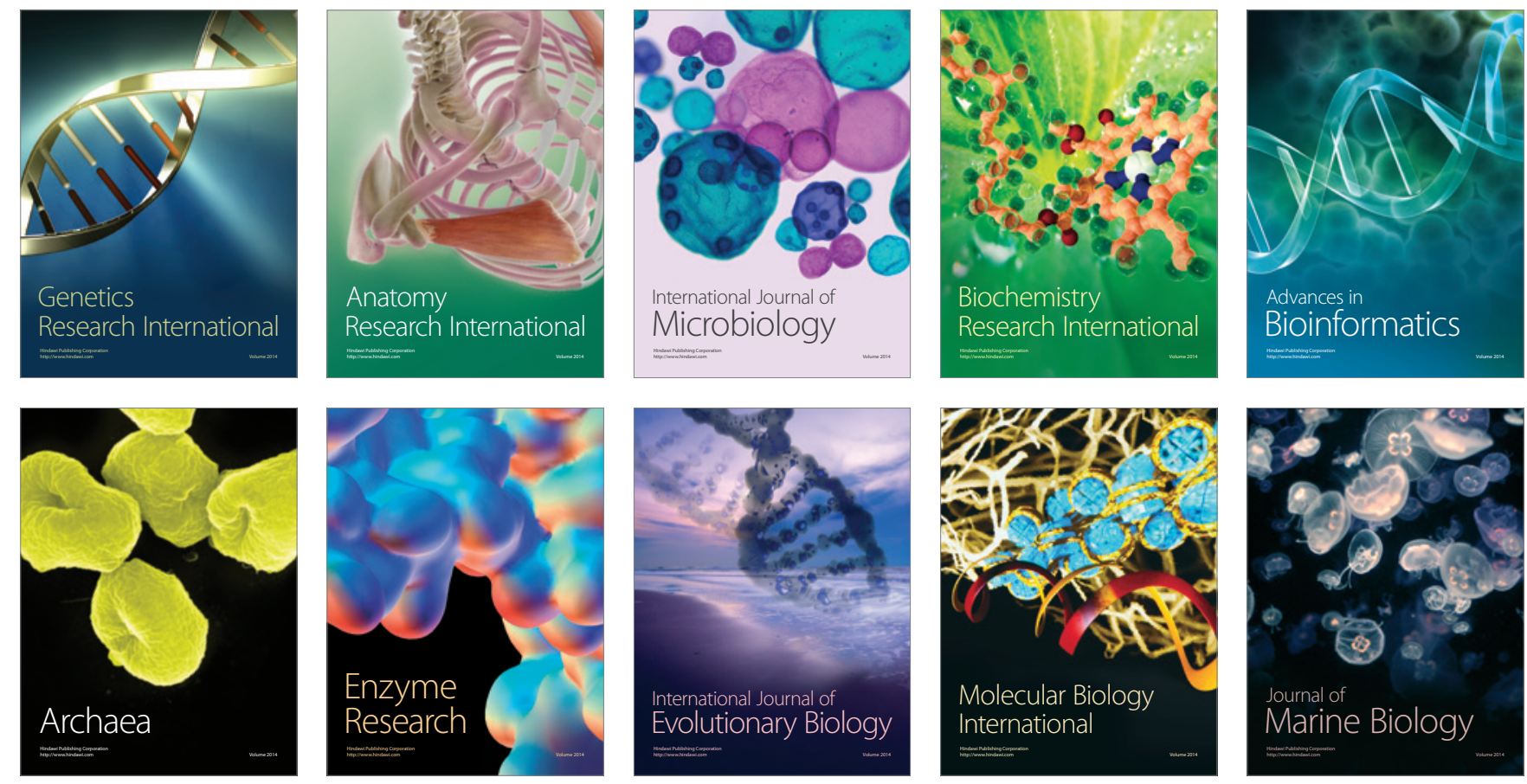